\title{
El intelectual y el compromiso docente en una sociedad democrática
}

\author{
Carlos Moya
}

Se acaba de morir Simón de Bouvoir: hace años ya que murió J. P. Sartre. Adorno y Horkheimer habian muerto para entonces; la desaparición de Fucault y el internamiento clínico de Althuser nos quedan más próximos. ¿Hasta qué punto el suicidio de Nikos Ponlantzas no fue equivalente -dentro de sus específicas coordenadas políticas, culturales - del hara-kiri de Mishima? En París, como en Tokio, se cumplía un trágico drama ritual: el intelectual sacrificialmente autodevorado por la específica pasión colectiva de identidad que hasta ese momento iluminó, enturbió, cegó su carismática voluntad de espíritu objetivo. Entender con el metaconcepto de Hegel, esa objetiva pasión de inteligencia singular, autoconsagrada a su pública manifestación como escritura, palabra y gesto al servicio de la posible $\longrightarrow$ imposible - patria que rige la voluntad de esa apasionada profesión de escriba. Para esa heróica figura de la modernidad occidental - forma contemporánea de lo que un mundo anterior -el de Israelfue vocación y oficio de profeta- su compulsivo deseo de patria deviene, en nuestro avanzado siglo agitado esfuerzo por mantener su imaginante sintonización de masas con la multiplicable audiencia y fugitivos públicos de su palabra escrita. En este vertiginoso tiempo nuestro la fama intelectual, la masiva sintonización entre un intelectual y su potencial público, es también, función de moda. Un tornadizo principio de acelerada obsolencia y permanente recambio, en la frenética oralidad estereofónica de nuestra democrática sociedad de consumo de masas. La soledad de un escritor, repitiéndose durante años sobre la misma mesa imaginaria, ¿qué puede frente a la omnipresente expansión tecno-social de los mass-media, configurando cada día la multiplicada y sucesiva rigidez de un cierto estilo de pensamiento y escritura, la acelerada obsolencia de argumentos y signos, rostros y nombres, deglutidos a la velocidad con que cambia la sensibilidad de masas que una vez alumbró su clamosoro éxito?

La patria de todo escritor, de todo intelectual, es su particular público, actual o potencial, imaginario o real; esa ausente e invisible masa de eventuales lectores y ocasionales oyentes que han de ser objetivos cómplices de la arquetípica figura de identidad, humanidad y mundo que mueve la pasión de entendimiento en libertad subyacente a esa profesión de pensamiento y escritura. La patria puede ser la propia nación o región, inmediata o ausente, gloriosa o atribulada: también, la postulada universalidad de una clase revolucionaria, o la lúcida libertad que otorga la autoafirmación como ciudadano del mundo: una decisiva herencia y posible imperativo que nos legaron los filosofos de la Stoen, hace unos veinte siglos. 
"En un estado libre es lícito a cada uno, no sólo pensar lo que quiera, sino decir aquello que piensa ... No es el fin del Estado convertir a los hombres de seres racionales en bestias o autómatas, sino por el contrario, que su espíritu y su cuerpo se desenvuelvan en todas sus funciones y hagan libre uso de la razón sin rivalizar por el odio, la cólera o el engaño, ni se hagan la guerra con ánimo injusto. El fin del estado es, pues, verdaderamente la libertad ... Esta libertad es necesaria ante todo para promover las ciencias y las artes, pues éstas sólo se cultivan con resultados por aquellos dichosos que tienen el juicio libre y sin preocupación en entendimiento" (Spinoza).

El último capítulo del Tractados Theologico político de Spinoza sigue siendo el texto clave de donde abarca toda la posterior historia occidental de la Democracia. Pues ahí se razona la última argumentación de tal fórmula política, su decisiva legitimación substancial: hacer posible, para todos y cada uno, una existencia política coherente con la postulada libertad racional de tales humanos.

Desde tiempos de Spinoza hasta el nuestro va mucha distancia, lo que entonces emergía como re-invención de la Democracia a partir de la guerra de liberación nacional de la República Holandesa, fue el gran argumento revolucionario que desde finales del siglo XVIII hasta nuestros días, se hizo movimiento histórico-universal y universalizada forma de Estado en una notable porción del planeta. Decisivo fue en esta larga historia el papel de los intelectuales: buena parte de los cuales, obligadamente, se reclutaron entre profesores y docentes de toda clase.

¿Qué pasa hoy con este argumento?

Toda una masa crítica de docentes habita en ese espacio intersticial. Su específica existencia se mueve en la modesta cotidianeidad de los escenarios académicos, las clases, los seminarios, los limitados recursos de investigación, la imposible rentabilidad económica de la letra impresa.

A caballo entre su trabajo en ese reducido "guetto" y su obligado consumo del babélico esplendor de los medios de masas, siguen apostando por la razón en libertad como plausible forma de existencia humana. Antes o después, aquello que se produce desde tan interiorizado compromiso, acaba por convertirse en posible consumo público, alli donde hay un mínimo aliento de creación. Y en esa forma, llega a hacerse espíritu objetivo y realimentación intelectual de nuestro vertiginoso siglo.

Max Weber contrapuso, decisivamente, la vocación del sabio y del político. Argumentó e interpretó magistralmente la específica figura de daimon que rige el destino de una profesión rigurosamente científica, advirtiendo frente a toda posible tentación de incitada demagogia, por las pasiones de masa que determina la pública profesión política y su posible carisma. Con ese magistral ensayo, a la vez que el rigor científico de Weber se nos transparece como arquetípica figuración del intelectual comprometido con la planetarizada humanidad occidental de su propio tiempo y nación. Sartre y Marcuse fueron penúltimas representación heróicas del intelectual universal postulando la Revolución. El modelo de profesión científica que cumplió Weber tiene más que ver con el intelectual específico que había argumentado Michel Foucault en sus últimos años. $Y$ así, necesariamente nos resulta más contemporáneo o acaso más lejano aún: pues este tiempo nuestro es posterior al viejo imperio ilustrado de la letra impresa, configurando lo que Maluhan bautizo "galaxia Gutemberg". El acelerado y expansivo desarrollo politi-tecnológico de los medios de comunicación de masas dirigiere con su 
cotidiana omnipresencia y multiplicado impacto el viejo teatro público de la escritura.

"Los mass-media -como dice Juan Cueto- son ante todo "productores de ídolos e idólatras en serie, centros emisores de lo espectacular, talleres del acontecimiento: factorías de lo histórico ... Han diseñado el acontecimiento - la materia prima de la historia - a su propia imagen y semejanza ... Se han erigido en el espacio de lo político y en el tiempo de lo social".

"El arte popular moderno al que aspiran los estetas hoy existe ya hace mucho tiempo y está formado por la masa de imágenes audiovisivas que nos asalta desde todas partes como nunca había ocurrido antes de este siglo. Esta masa comprende todo, incluso lo que en otros tiempos se había definido como arte ... Dentro de algunos decenios, probablemente la guerra fría en pro y en contra de los mass media se mostrará carente de sentido". Montale escribe en 1964, en pleno auge intelectual de la disputa de la "cultura de masas" y la "industria cultural". En 1972 a la hora de publicar "Del Nostro Tempo" - su testamento poético- seguirá mantenido su argumento: "Las hipótesis optimistas avanzan la suposición de que el hombre permanecerá extraño a la máquina, no será modificado, absolutamente por ella e incluso estará en condiciones de dirigirla a los mejores fines, mientras que la observación demuestra que el hombre masa quiere, crear su propio destino, $y$, a tal efecto se procura los instrumentos necesarios. Las utilidades de masa constituyen el fundamento no sólo de la industria pesada, sino de toda la nueva industria cultural, llevada, fatalmente a ampliarse sobre planos cada vez más bajos, una vez alcanzados, los cuales, siempre será posible esperar en nuevas bajuras realizando las hipótesis de un futuro hombre estereofónico, incapaz hasta de reflexionar sobre su propia suerte".

¿Cómo no advertir sobre nuestra alcanzada modernidad la evidente realización de la hipótesis de Montale? Otra cosa es que debamos poner entre paréntesis la inmediata connotación pesimista del gran poeta italiano. Montale murió hace cuatro affos: nuestro tiempo, posterior al suyo, reclama un particular esfuerzo de análisis y reflexión. Para enfrentarlo con suficiente despejo, utilizamos su precisa metáfora; nos abre los ojos para mirar nuestra inmediata actualidad entorno.

Todo el novísimo complejo electrónico de los media se impone e incorpora a sus consumidores individuales desde la doméstica privacidad de su originario hogar familiar hasta la de su posterior piso/apartamento matrimonial o celibatario, presidiendo su frenética o depresiva circulación exterior. Habitando la cotidiana intimidad doméstica de los sobreurbanizados accidentales, configurando sus novísimos ritos tribales de masa, esa novísima y compleja extensión del aparato audiovisual corporal, presidida por la televisión, ha desencadenado una mutación de todo tipo de relaciones sociales: una decisiva implosión de "lo social". Desde el espacio interior de las relaciones familiares al planeta exterior del Poder adulto, en reiterativo circuito de ida y vuelta, se dispara una explosiva crisis del tabú patriarcal del incesto. El quicio ancestral del Orden social - la norma de las normas - (L. Strauss) regulando la interrelación de las clases de sexo y la edad en la producción y reproducción de la identidad colectiva y la identidad personal - hizo explosición entre los ańos 60 y el comienzo de los 70. En aquella misma llamarada libertaria y gloriosa alucinación colectiva con que estalló la galaxia de Gutemberg. Acabóse la letra impresa del libro como forma hegemónica de representación simbólica del mundo humano, trascendentalmente 
regido por la Razón con mayúsculas. Lo propio de nuestro avanzado tiempo, posterior al literario imperio de la Ilustración, es el salto a una cultura de masas semióticamente autorregulables en términos de flujos audiovisuales/mass media y bits de información.

Toda suerte de relaciones sociales e interpersonales y sus particulares usos del habla surge así una radical metamorfosis. Se dispara el apocalipsis simbólico de un ciclo histórico agotado, arrasado por el vertiginoso avance de la tercera ola. Su omnipresente impacto nos obliga a saltar más allá de los absoletos límites del Neolítico industrial eurocéntrico. Lo que empezamos a ver del nuevo tiempo emergente nos autoriza a conjurar los riesgos de su insidiosa pesadilla orwelliana. La amenaza de un orden total, basado en el control vídeo-telemático de sus computarizados súbditos, no es sino el rostro invertido de la ilusión cibernética imaginando una Sociedad definitivamente programada.

Lo que tipifica a la Democracia industrial de masas, en su inmediato horizonte post-industrial, post-histórico, es su decisiva metamorfosis telemático-estereofónica. En esta forma, la conjunción tecnotrónica de telecomunicaciones, ordenadores y massmedia preside el salto hacia el futuro de nuestro planetarizado tiempo. Así como con la Revolución Francesa los hombre de letras seglares desplazaron a los clérigos y teólogos del Antiguo Régimen, con la mutación estereofónica de la Democracia industrial de masas los profesionales de los nuevos media desplazan a los antiguos profesores e intelectuales que una vez concentró la plural Academia literaria vertebrada en torno a la Universidad y el Parlamento. Desde su conjunción electrónica con la revolución informática, los mass-media de nuestros días hegemonizan la ilustración pública de masas. De ahí su decisiva responsabilidad colectiva, su propio riesgo profesional, su fluctuante quantum de auto-intoxicación y sobredosis.

De momento, lo que parece seguro es que el progresivo desarrollo de las nuevas tecnologías y medios de comunicación, es rigurosamente coetáneo de una progresiva privatización del comportamiento espontáneo personal, correspondiente a la sobredomesticación tecno-burocrática que invade el viejo espacio público de la libre responsabilidad y espontaneidad individual. La progresiva articulación telemáticoestereofónica de las relaciones de dominación en nuestro tiempo parece reforzar el poder de cuadros organizados y masas teleadictas, alli donde se produce y mantiene su efímera conexión/identificación con sus fugaces ídolos seriales. Acelerada saturación y absolencia de los multiplicados personajes y argumentos capaces de sintonizar y seducir las ambivalentes pulsiones de sus masivas y plurales audiencias.

La penúltima vanguardia crítica insistió una y otra vez en la perfidia de los manipuladores de masas. Desde nuestro tiempo, posterior al de Adorno, Mills y Marcuse, empezamos a entender algo un tanto distinto. Por encima y por debajo de toda suerte de maquinaciones y manipuladores particulares, las plurales masas y muchedumbres solitarias de nuestro sobreurbanizado tiempo se hablan entre sí a través de los media. A través de su compleja pluralidad multidireccional. En el uso de tan propio y tecnotrónico discurso, las masas producen y consumen, exaltan y devoran la particular existencia de aquellos que se imaginan sus gloriosos héroes y audaces maquinadores. Por lo demás, la propia articulación mítico-ritual de la Democracia industrial de masas y su expansivo mercado tecnotrónico-informático aseguran notables límites de tolerancia para las plurales disidencias y marginaciones que esa colectiva 
maquinaria produce y reproduce.

Que los próximos treinta afios sigan teniendo que ver con la ancestral apuesta de razón y libertad que funda y encarna nuestra conquistada Democracia, va a depender, decisivamente, de la inmediata y sucesiva capacidad de todos para seguir manteniendo ese imperativo legado de la moderna Ilustración. Objetivo espíritu del Ciclo heróico de la Modernidad que ahora concluye en el amnésico esplendor multimedia de la nueva era informática. En sus intersticios, colegios invisibles de letra impresa y apasionadas discusiones esotéricas, siguen produciendo, discretamente, las sucesivas palabras y ecuaciones con que se preserva y recrea, silenciosamente, la multiplicada memoria poética del mundo humano.

Podemos hablar y discutir en multiplicables formas del tema que aquí nos reúne. El intelectual y el compromiso docente en una sociedad democrática. Podíamos haber centrado estas reflexiones en el canonizado modelo de "intelectual orgánico" que argumentó y vivió Gramsci en la cárcel. O haber puesto en examen esa secuencia arquetípica que va desde Kant y Fichte a Hegel y Marx —máxima secuencia heróica de la Ilustración europea en manos de docentes, cuya sucesiva iluminación y compromiso intelectual con su propio tiempo y voluntad de Razón universal elevó sus particulares textos y escrituras a Evangelio heróico de la Modernidad Occidental.

En cualquier modo, nuestra posible reflexión se monta obligadamente, sobre las espaldas de todos esos gigantes o fugitivos escritores, como los ya citados. Pues todos ellos en una u otra forma contribuyeron a determinar a su particular aire y estilo, el compromiso del intelectual y del docente con su propio tiempo, con su obligado, mutable, fugitivo público. Hasta convertirse en agotada sustancia mortal del espíritu objetivo que mueve la pasión de leer, escribir, hablar, haciéndose pública profesión docente e ilustración pública de masas.

Supuesto el radical pluralismo que autolegitima nuestra alcanzada Democracia, supuesta la singularizada pasión de libertad y razón que impone tal título de ciudadania, podemos, entre todos, dar vueltas y discutir, lo hasta aquí leído. Ello será la mejor forma de dar ahora cumplimiento final a la simbólica convocatoria que hoy nos reúne y compete.

Con un poco de suerte podremos alcanzar así alguna claridad sobre el doblete intectual/docente enmarcado ahora en la estereofónica mutación semiótica y existencial que rige la inmediata actualidad y futuro de nuestra Democracia industrial de masas. 